\title{
Avian Influenza A Viruses among Occupationally Exposed Populations, China, 2014-2016
}

\author{
Chuansong Quan, ${ }^{1}$ Qianli Wang, ${ }^{1}$ Jie Zhang, Min Zhao, Qigang Dai, Ting Huang, \\ Zewu Zhang, Shenghua Mao, Yifei Nie, Jun Liu, Yun Xie, Baorong Zhang, Yuhai Bi, Weifeng Shi, \\ Peipei Liu, Dayan Wang, Luzhao Feng, Hongjie Yu, William J. Liu, George F. Gao
}

To determine the seroprevalence and seroconversion of avian influenza virus (AIV) antibodies in poultry workers, we conducted a seroepidemiologic study in 7 areas of China during December 2014-April 2016. We used viral isolation and reverse transcription PCR to detect AIVs in specimens from live poultry markets. We analyzed 2,124 serum samples obtained from 1,407 poultry workers by using hemagglutination inhibition and microneutralization assays. We noted seroprevalence of AIV antibodies for subtypes H9N2, H7N9, H6N1, H5N1-SC29, H5N6, H5N1-SH199, and H6N6. In serum from participants with longitudinal samples, we noted seroconversion, with $\geq 4$-fold rise in titers, for H9N2, H7N9, H6N1, H5N1-SC29, H6N6, H5N6, and H5N1-SH199 subtypes. We found no evidence of $\mathrm{H} 10 \mathrm{~N} 8$ subtype. The distribution of AIV antibodies provided evidence of asymptomatic infection. We found that AIV antibody prevalence in live poultry markets correlated with increased risk for H7N9 and H9N2 infection among poultry workers.

Author affiliations: National Institute for Viral Disease Control and Prevention, Chinese Center for Disease Control and Prevention, Beijing, China (C. Quan, J. Zhang, P. Liu, D. Wang, W.J. Liu, G.F. Gao); Shandong First Medical University \& Shandong Academy of Medical Sciences, Jinan, China (C. Quan, W. Shi); Fudan University School of Public Health, Shanghai, China (Q. Wang, H. Yu); Institute of Microbiology, Chinese Academy of Sciences, Beijing (M. Zhao, Y. Bi, G.F. Gao); Jiangsu Provincial Center for Disease Control and Prevention, Nanjing, China (Q. Dai); Sichuan Provincial Center for Disease Control and Prevention, Chengdu, China (T. Huang); Dongguan Municipal Center for Disease Control and Prevention, Dongguan, China (Z. Zhang); Shanghai Municipal Center for Disease Control and Prevention, Shanghai (S. Mao); Henan Provincial Center for Disease Control and Prevention, Zhengzhou, China

(Y. Nie); Zaozhuang Center for Disease Control and Prevention, Zaozhuang, China (J. Liu); Jiangxi Provincial Center for Disease Control and Prevention, Nanchang, China (Y. Xie); Aviation General Hospital, Beijing (B. Zhang); Chinese Center for Disease Control and Prevention, Beijing (L. Feng, G.F. Gao)

DOI: https://doi.org/10.3201/eid2512.190261
$\mathrm{H}$ uman infection with avian influenza viruses (AIVs) has been reported in China since the late 1990s. Since then, human infections with subtypes H5N1, H5N6, H6N1, H7N4, H7N9, H9N2, and H10N8 have been reported continuously and are a substantial threat to public health in the country (1-5). Birds at wholesale and retail live poultry markets are recognized incubators for novel influenza virus subtypes (6-9). Because of special occupational characteristics, poultry workers are at a high risk for repeated exposure to AIV-infected poultry. Most case-patients with H7N9 infection have had a history of contact with live poultry, and poultry workers represent a substantial proportion of cases (10). Several studies on AIV seroprevalence in occupationally exposed populations suggest that asymptomatic or clinically mild AIV infections are extensively prevalent among poultry workers (11-14). A serologic study of AIV distribution among poultry workers could directly evaluate the potential for AIVs to cross the species barrier to infect humans and might illuminate the current understanding of AIV prevalence in live poultry markets (15).

Low pathogenicity avian influenza $\mathrm{A}(\mathrm{H} 9 \mathrm{~N} 2)$ virus is distributed widely in domestic poultry around the world. A systematic review reports $\mathrm{H} 9 \mathrm{~N} 2$ virus seroprevalence in avian-exposed populations ranges from $1 \%$ to $43 \%$ by hemagglutination inhibition (HI) assays (16). Since a 2013 H7N9 infection outbreak in China, caused by a novel reassortant influenza $\mathrm{A}(\mathrm{H} 7 \mathrm{~N} 9)$ virus and associated with severe human infections, seroprevalence of the H7N9 subtype has been reported to range from $6 \%$ to $14.9 \%$ in southern China $(17,18)$. In a previous study, the seroprevalence of H5 subtype AIVs in poultry workers was relatively low, whereas a cross-sectional study conducted in Zhejiang Province reported a seroprevalence of 4.7\% for H5N1 virus antibodies (19).

Few large-scale longitudinal seroepidemiologic studies have included multiple AIV subtypes in diverse epidemic regions, especially after emergence of novel

${ }^{1}$ These authors contributed equally to this article. 
subtypes. We conducted a prospective seroepidemiologic study in 7 representative areas across China to address gaps in the research. We characterized the seroprevalence profiles of 7 dominant human-infecting AIV subtypes among occupationally exposed workers in live poultry markets. Our aim was to further analyze human AIV infection risks for serotypes common in occupational exposure, including H5N1, H5N6, H6N1, H6N6, H7N9, H9N2, and H10N8 virus subtypes.

\section{Methods}

\section{Ethics Approval}

This study was approved by the Ethics Review Committee of the National Institute for Viral Disease Control and Prevention, Chinese Center for Disease Control and Prevention. The study was conducted in accordance with the principles of the Declaration of Helsinki and the standards of Good Clinical Practice as defined by the International Conference on Harmonization (https://www.ich.org).

\section{Study Design and Participants}

During December 2014-April 2016, we conducted a longitudinal seroepidemiologic study to assess asymptomatic AIV infection levels among poultry workers in China. We defined poultry workers as persons who repeatedly are exposed to poultry and work in wholesale or retail live poultry markets or in backyard farms, including wholesale sellers, retail sellers, transporters, processors, or feeders. The study included 1 municipality, Shanghai, and 6 provinces, Guangdong, Henan, Jiangsu, Jiangxi, Shandong, and Sichuan (Figure 1, panels A and B; Appendix, https://wwwnc.cdc.gov/EID/ article/25/12/19-0261-App1.pdf). The study design included 4 serologic surveys. We collected whole blood samples from participating poultry workers at an initial visit in December 2014 and again during 3 consecutive follow-up visits in April 2015, December 2015, and April 2016 (Figure 1, panel C).

We used a standardized questionnaire to collect information at initial participant enrollment and updated participant information at subsequent visits. Participant information collected was demographic data, exposure variables, whether the worker experienced influenza-like illness within the previous month, and whether they received a seasonal influenza vaccination within the previous 12 months (Appendix).

Some poultry workers in China are short-term employees with high population mobility. We attempted to conduct follow-up studies with these employees through assistance from the market managers. To ensure the sample size, we enrolled new participants at each visit to the poultry markets (Figure 2).

We also recruited a control group of 216 outpatients with noninfectious diseases on physical examination at a general hospital in Beijing in October 2015. We collected 216 serum samples from the control group.

\section{Collection of Human Samples}

We collected a single venous whole blood sample from each study participant at each visit by using a Vacutainer blood collection tube (Becton Dickinson, https://www. bd.com). We divided serum into 3 aliquots and froze at $-80^{\circ} \mathrm{C}$ until testing.

\section{Serologic Assays}

We tested participant serum samples for antibodies against H5N1, H5N6, H6N1, H6N6, H7N9, H9N2, and H10N8 virus subtypes, as well as for antibodies against seasonal influenza $\mathrm{A}(\mathrm{H} 1 \mathrm{~N} 1) \mathrm{pdm} 09$ ( $\mathrm{pH} 1 \mathrm{~N} 1)$ and $\mathrm{H} 3 \mathrm{~N} 2$ viruses, to exclude cross-reactivity. We selected available representative antigens on the basis of their antigenic characteristics (Table 1) and analyzed the relevant phylogenetic relationship of hemagglutinin (HA) genes (Appendix Figures 1-5).

We performed all serologic assays in a Biosafety Level 2 or 3 laboratory. First, we screened samples by using an $\mathrm{HI}$ assay for antibodies, as described previously (20). We tested serum samples at a starting dilution of 1:10, followed by a 2 -fold dilution to the endpoint (Appendix). To confirm $\mathrm{HI}$ assay results, we performed a microneutralization (MN) assay on serum samples with an HI titer $\geq 1: 20$ to H5N1, H5N6, H6N1, H6N6, H7N9, or H10N8 subtypes and those with an $\mathrm{HI}$ titer $\geq 1: 40$ to H9N2, pH1N1, or H3N2 subtypes, as previously described (20).

We used HI and MN cutoff values in accordance with previously published data (Appendix Table 1). We considered $\geq 1: 20$ as the cutoff value for $\mathrm{HI}$ and $\mathrm{MN}$ titers for positive tests for H5N1, H5N6, H6N1, H6N6, H7N9, and $\mathrm{H} 10 \mathrm{~N} 8$ virus subtypes $(11,12,21)$ and considered $\geq 1: 40$ as the cutoff value for $\mathrm{HI}$ titer and $\geq 1: 80$ as the cutoff value for $\mathrm{MN}$ titer for positive tests for $\mathrm{H} 9 \mathrm{~N} 2$, pH1N1, and H3N2 virus subtypes $(22,23)$. We set a stricter dilution cutoff value for the H9N2 virus subtype. An HI titer of 1:40 commonly is used and generally is an accepted value for influenza serologic assays used in detection of seasonal influenza and avian influenza H9 infection (24). We considered participants to have seroconversion when they had a $\geq 4$-fold rise in antibody titer measured by $\mathrm{HI}$ assay between collection of $\geq 1$ serum samples, plus an MN titer value of the later specimen being $\geq 1: 20$ or $\geq 1: 80$ for H9N2 subtype only.

\section{Isolation of AIVs from Environmental and Poultry Samples}

For environmental and poultry samples, we used previously described sampling and detection methods (25). In brief, we randomly selected environmental sites and poultry to sample by using a multistage sampling strategy. We collected environmental samples by swabbing water 
A

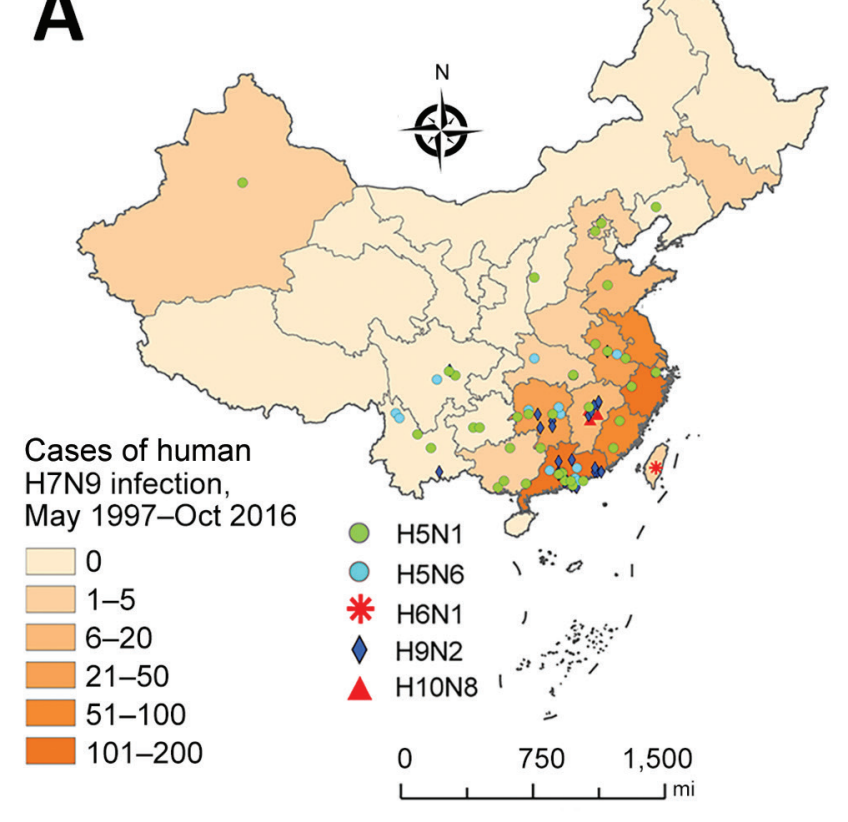

C

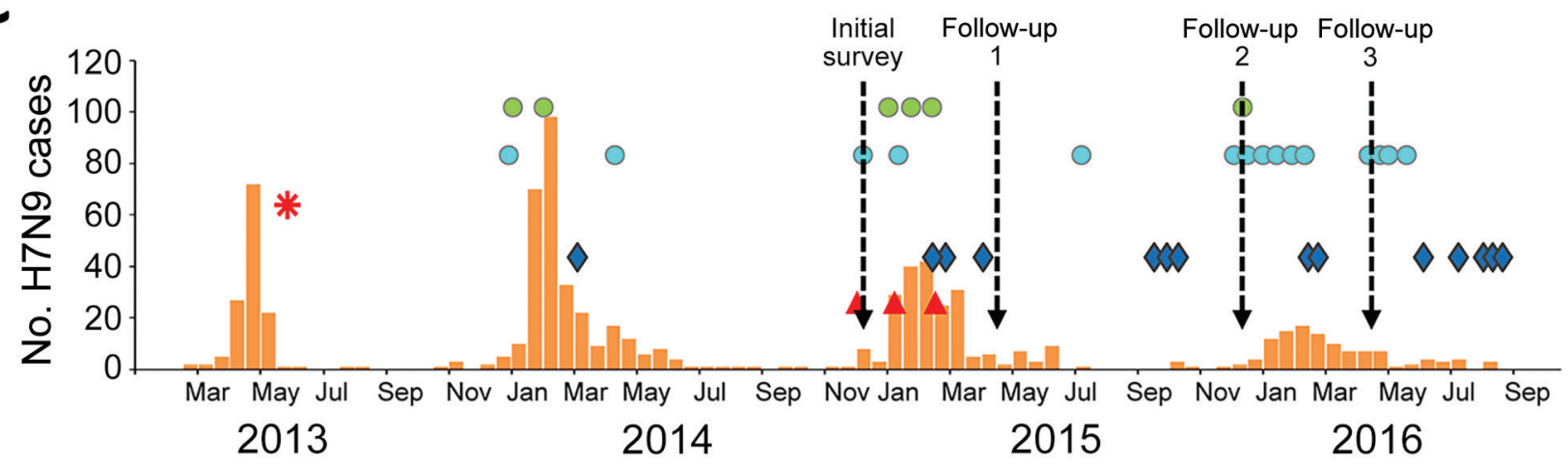

Figure 1. Temporal and spatial distribution of human infections with avian influenza A virus subtypes before and during serosurveillance, China. A) Geographic distribution of avian influenza A(H7N9) virus infection among humans in China during May 1997-October 2016. The number of case-patients in each province is based on data published by the World Health Organization (https://www.who.int/influenza/ human_animal_interface/avian_influenza/archive/en/) and the National Health and Family Planning Commission of the Republic of China (http://www.nhc.gov.cn/jkj/s2907/new_list.shtml?tdsourcetag=s_pcqq_aiomsg). Density of shading represents the number of reported avian influenza H7N9 cases in humans in each province. Cases of other AIV subtype infections are represented by other symbols. B) Density of live poultry markets per 10,000 persons in each province included in the study, from data collected during 2013-2014. Red flags indicate locations of poultry markets selected for the serosurveillance study. C) Distribution of biweekly cases of human H7N9 infection before and during serosurveillance study. Orange bars indicate the number of biweekly cases of human H7N9 infection. Dashed lines indicate initial survey and follow-up dates for serosurveys, which were conducted before and after the third and fourth wave H7N9 epidemics. Reported cases of H5N1, H5N6, H6N1, H9N2, and H10N8 infection are noted with symbols as in panel A. AIV, avian influenza virus.

troughs, floors, and drains in poultry enclosures and collected oropharyngeal and cloacal swabs from apparently healthy poultry. We isolated avian influenza viruses in 9- to 10-day-old specific pathogen-free chicken embryos by using viral isolation procedures and following World Health Organization guidelines (20). We further analyzed hemagglutinin-positive samples by using reverse transcription PCR (RT-PCR) to identify hemagglutinin (HA) and neuraminidase (NA) genetic subtypes (20). Except for Shandong Province, we detected AIVs from domestic poultry and live poultry market environments in all study areas.

\section{Data Analysis}

Our analyses were based on seroepidemiologic studies for influenza published by Horby et al. (26). We assigned each participant a unique identifier and used all data collected 


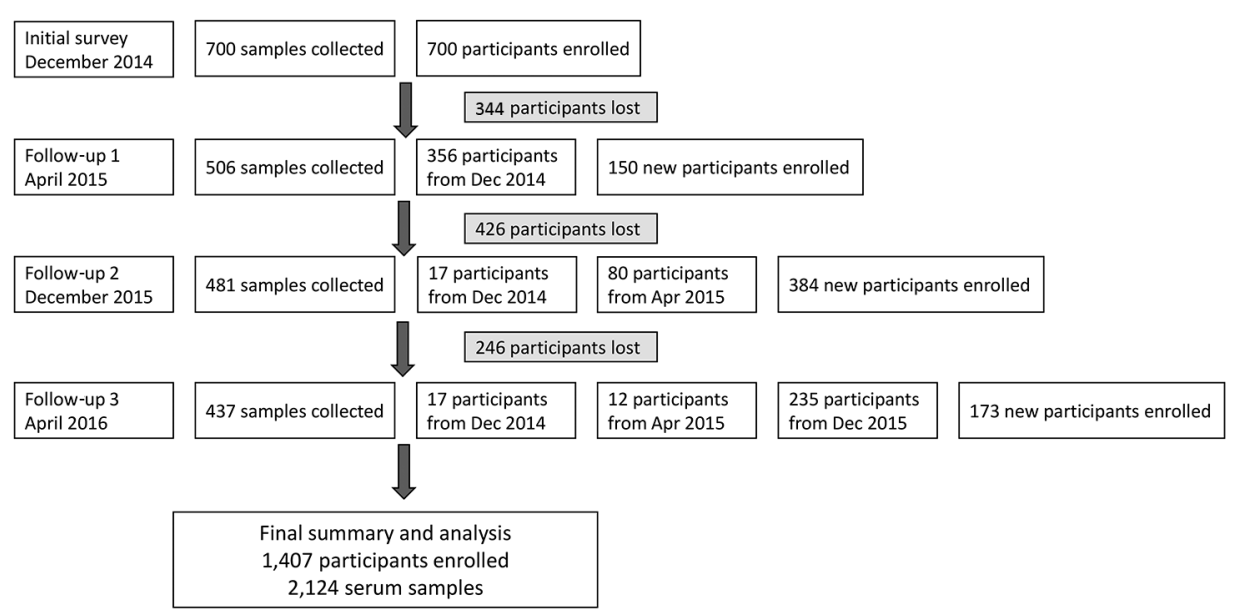

Figure 2. Flowchart of initial participant enrollment and follow-up distribution in 7 areas of China in a study of avian influenza virus seroprevalence during December 2014April 2016. with the questionnaire to establish a database. We performed a multivariate logistic regression model to evaluate independent risk factors associated with seroprevalence of antibodies in poultry workers. Risk factors evaluated were age; sex; occupational exposure factors, including processing, selling, transporting, and feeding poultry; and seropositivity to human influenza $\mathrm{pH} 1 \mathrm{~N} 1$ or $\mathrm{H} 3 \mathrm{~N} 2$ viruses. For logistic regression analysis, we estimated the maximum likelihood for the odds ratio (OR) and calculated 95\% CIs by using the Wald $\chi^{2}$ test. We used binomial distribution to calculate $95 \%$ CIs of rate. We used Spearman correlation analysis to estimate the association between seroprevalence and local epidemic intensity of AIVs in live poultry markets by region. We used 2-tailed $p$ values for all calculations and considered values $<0.05$ statistically significant. We performed statistical analyses by using SAS 9.4 (SAS Institute, Inc., https://www.sas.com).

\section{Results}

\section{Participant Characteristics}

We collected 2,124 serum samples from 1,407 participants from 1 municipality, Shanghai, and 6 provinces, Guangdong, Henan, Jiangsu, Jiangxi, Shandong, and Sichuan, in China. We had paired or serial serum samples from 652 participants who had $\geq 2$ visits during the study period. The median age of participants with completed questionnaire information was 46 years (interquartile range [IQR] 36-52 years); $54.0 \%(1,147 / 2,124)$ of samples were from men. The most common category of poultry exposure was poultry seller. We did not see statistically significant differences in the distribution of demographic characteristics of participants, including sex and age, over the 4-period survey. In addition, $2.8 \%(59 / 2,124)$ of samples came from poultry workers who reported receiving a seasonal influenza vaccine within the previous 12 months (Table 2).

Of the 216 participants in control group, the median age was 48 years (IQR $34-59$ years); $45.8 \%$ were male. We saw no significant differences in their data compared with poultry workers (data not shown).

\section{Seroprevalence of Antibodies against AIVs}

In the 2,124 samples, the overall seroprevalence of antibodies was $11.2 \%$ for H9N2 subtype and $3.9 \%$ for H7N9 subtype. Seroprevalence for $\mathrm{H} 5 \mathrm{Nx}$ and $\mathrm{H} 6 \mathrm{Nx}$ subtypes was lower, ranging from $1.3 \%$ to $2.1 \%$ for $\mathrm{H} 5 \mathrm{Nx}$ and from $0.4 \%$ to $2.5 \%$ for H6Nx. We did not observe evidence of H10N8 infection (Table 3).

The seroprevalence profile was geographically distinct (Figure 3). For example, in Shandong Province, H9N2

\begin{tabular}{|c|c|c|}
\hline Subtype & Virus strain & GISAID number \\
\hline \multicolumn{3}{|l|}{ Avian influenza } \\
\hline H5N1 clade 2.3.2.1c & A/chicken/Shanghai/02.12 HZ199-P/2015 (SH199) & EPI1544294 \\
\hline H5N1 clade 2.3.4.4 & A/pigeon/Sichuan/NCXN29/2014 (SC29) & EPI590898 \\
\hline H5N6 clade 2.3.4.4 & A/duck/Guangdong/04.22 DGCP069-O/2015 & EPI660071 \\
\hline $\mathrm{H} 6 \mathrm{~N} 1$ & A/Taiwan/2/2013 & EPI459855 \\
\hline H6N6 & A/duck/Guangxi/04.10 JX031/2015 & EPI661887 \\
\hline H7N9 & A/chicken/Guangdong/04.22 DGCP098-O/2015 & EPI666285 \\
\hline H9N2 & A/chicken/Guangdong/04.15 SZBAXQ005/2015 & EPI661935 \\
\hline H10N8 & A/chicken/Jiangxi /B18/2014 & EPI1544302 \\
\hline \multicolumn{3}{|l|}{ Seasonal influenza } \\
\hline H1N1(pdm09) & A/California/04/2009 & EPI176470 \\
\hline H3N2 & A/Beijing/CAS0001/2007 & EPI1544286 \\
\hline
\end{tabular}


Influenza Viruses among Occupationally Exposed Populations

Table 2. Characteristics of study participants in serosurveys for avian influenza viruses, China, 2014-2016*

\begin{tabular}{|c|c|c|c|c|c|c|c|}
\hline Variables & $\begin{array}{c}2014 \mathrm{Dec} \\
\mathrm{n}=700\end{array}$ & $\begin{array}{c}2015 \mathrm{Apr} \\
\mathrm{n}=506\end{array}$ & $\begin{array}{c}2015 \mathrm{Dec} \\
\mathrm{n}=481\end{array}$ & $\begin{array}{c}2016 \mathrm{Apr} \\
\mathrm{n}=437\end{array}$ & $\begin{array}{c}\text { Total, } \\
\mathrm{n}=2,124\end{array}$ & $\chi^{2} \dagger$ & $p$ value \\
\hline \multicolumn{8}{|l|}{ Sex, no. (\%) } \\
\hline M & 369 (52.7) & $264(52.2)$ & $278(51.8)$ & $236(54.0)$ & $1,147(54.0)$ & 3.94 & 0.27 \\
\hline $\mathrm{F}$ & 331 (47.3) & $242(47.8)$ & $203(42.2)$ & $201(46.0)$ & $977(46.0)$ & & \\
\hline \multicolumn{8}{|l|}{ Age, y, no. (\%)‡ } \\
\hline$<21$ & $10(1.4)$ & $6(1.2)$ & $4(0.8)$ & $11(2.5)$ & $31(1.5)$ & 1.43 & 0.23 \\
\hline $21-40$ & $212(30.3)$ & $144(28.5)$ & $164(34.1)$ & $144(33)$ & $664(31.3)$ & & \\
\hline $41-60$ & 394 (56.3) & $308(60.9)$ & $254(52.8)$ & 232 (53.1) & $1,188(55.9)$ & & \\
\hline$>60$ & $78(11.1)$ & $47(9.3)$ & $55(11.4)$ & $50(11.4)$ & $230(10.8)$ & & \\
\hline Missing data & $6(0.9)$ & $1(0.2)$ & $4(0.8)$ & 0 & $11(0.5)$ & & \\
\hline Median age (range) $\S$ & $46(38-52)$ & $47(38-52)$ & $45(35-52)$ & $45(35-52)$ & $46(36-52)$ & 6.62 & 0.08 \\
\hline \multicolumn{8}{|l|}{ Type of poultry exposure, no. (\%)ף } \\
\hline Processing & $155(22.1)$ & $107(21.1)$ & $118(24.5)$ & $94(21.5)$ & $474(22.3)$ & 27.88 & 0.006 \\
\hline Selling & $423(60.4)$ & $332(65.6)$ & $299(62.2)$ & $191(43.7)$ & $1,243(58.5)$ & & \\
\hline Transportation & $39(5.6)$ & $31(6.1)$ & $24(5)$ & $21(4.8)$ & $115(5.4)$ & & \\
\hline Feeding & $191(27.3)$ & $125(24.7)$ & $124(25.8)$ & $93(21.3)$ & $533(25.1)$ & & \\
\hline Others & $59(8.4)$ & $35(6.9)$ & $25(5.2)$ & $48(11)$ & $167(7.9)$ & & \\
\hline Missing data & 0 & 0 & $2(0.4)$ & 0 & $2(0.1)$ & & \\
\hline Length of poultry exposure, y (range)§ & $8(3-15)$ & $8(3-15)$ & $5(2-10)$ & $5(3-10)$ & $6(3-13)$ & 61.63 & $<0.001$ \\
\hline Vaccinated against seasonal influenza, no. (\%) & $23(3.3)$ & $8(1.6)$ & $20(4.2)$ & $8(1.8)$ & $59(2.8)$ & 8.20 & 0.04 \\
\hline \multicolumn{8}{|l|}{$\begin{array}{l}\text { *Some participants participated in }>1 \text { survey. } \\
\text { †By } \chi^{2} \text { test, unless otherwise indicated. } \\
\text { †By } \chi^{2} \mathrm{CMH} \text { test. Missing data were not calculated. } \\
\S \text { By Kruskal-Wallis test. }\end{array}$} \\
\hline
\end{tabular}

virus antibody seroprevalence was $23 \%$, which was higher than in other provinces, especially Sichuan Province, which had only a $4.2 \%$ seroprevalence for this subtype. Provinces in the Yangtze River Delta, which were the first to report H7N9 infections in patients during the 2013 outbreak, exhibited higher seroprevalence rates compared with the other provinces. Shanghai had a rate of $10.3 \%$ and Jiangsu Province had a rate of $6.9 \%$. In Sichuan Province, where a non-laboratory-confirmed H7N9-infected patient was reported before 2017, no participant tested positive for the H7N9 subtype.

Seroprevalence of H5 and H6 subtypes among poultry workers also were different by region. Detected H5 subtypes included H5N1-SH199 clade 2.3.2.1c in 5.3\% of samples from Shandong Province; H5N1-SC29 clade 2.3.4.4 in 3.0\% of samples from Jiangsu Province and in $3.3 \%$ of samples from Sichuan Province; and H5N6 in 4.9\% of samples from Shanghai. We detected H6N1 in 5.2\% of samples from Jiangsu Province and in 3.8\% from Shanghai and H6N6 in 3.3\% of samples from Shanghai (Figure 3).
Among the 216 participants in the control group, we found no evidence of antibodies against H7N9 virus and a lower prevalence $(3.7 \%)$ of antibodies against H9N2 virus than in the poultry workers. We observed no statistically significant differences in the prevalence of antibodies against other AIV subtypes between the control group and poultry workers (Appendix Table 2).

\section{Seroconversion of Antibodies against AIVs among Poultry Workers}

We observed seroconversion in all AIV antigens during the study period, except the H10 subtype, which might represent a new asymptomatic AIV infection among poultry workers (Figure 4, panel A). Among 652 poultry workers with paired or serial serum samples during the study, 3.5\% demonstrated seroconversion for H9N2 virus, $1.4 \%$ demonstrated seroconversion for $\mathrm{H} 7 \mathrm{~N} 9$ virus, and $<1 \%$ demonstrated seroconversion for $\mathrm{H} 5$ or $\mathrm{H} 6$ viruses (Figure 4, panels B and C; Appendix Tables 3-9). Because we saw no evidence of $\mathrm{H} 10 \mathrm{~N} 8$ virus, we also

\begin{tabular}{lccccc}
\hline \multicolumn{7}{c}{ Table 3. Seroprevalence among poultry workers surveyed for avian influenza viruses, China, 2014-2016* } \\
\hline \multicolumn{5}{c}{ No. $\%, 95 \% \mathrm{Cl})$ seropositive participants } \\
\cline { 2 - 6 } Antigen & $2014 \mathrm{Dec}, \mathrm{n}=700$ & $2015 \mathrm{Apr}, \mathrm{n}=506$ & $2015 \mathrm{Dec}, \mathrm{n}=481$ & $2016 \mathrm{Apr}, \mathrm{n}=437$ & Total, $\mathrm{n}=2,124$ \\
\hline Avian influenza serotype & & & & \\
H5N1-SH199 & $6(0.9,0.2-1.5)$ & $6(1.2,0.2-2.1)$ & $10(2.1,0.8-3.4)$ & $6(1.4,0.3-2.5)$ & $28(1.3,0.8-1.8)$ \\
H5N1-SC29 & $22(3.1,1.8-4.4)$ & $17(3.4,1.8-4.9)$ & $2(0.4,0.1-1.5)$ & $3(0.7,0.1-2.0)$ & $44(2.1,1.5-2.7)$ \\
H5N6 & $28(4,2.5-5.5)$ & $11(2.2,0.9-3.4)$ & $2(0.4,0.1-1.5)$ & $1(0.2,0-1.3)$ & $42(2.0,1.4-2.6)$ \\
H6N1 & $22(3.1,1.8-4.4)$ & $21(4.1,2.4-5.9)$ & $5(1,0.1-1.9)$ & $5(1.1,0.4-2.6)$ & $53(2.5,1.8-3.2)$ \\
H6N6 & $0(0,0-0.5)$ & $0(0,0-0.7)$ & $7(1.5,0.4-2.5)$ & $1(0.2,0-1.3)$ & $8(0.4,0.1-0.6)$ \\
H7N9 & $33(4.7,3.1-6.3)$ & $36(7.1,4.9-9.4)$ & $6(1.3,0.3-2.2)$ & $7(1.6,0.4-2.8)$ & $82(3.9,3.0-4.7)$ \\
H9N2 & $48(6.9,5.0-8.7)$ & $59(11.7,8.9-14.5)$ & $64(13.3,10.3-16.3)$ & $66(15.1,11.7-18.5)$ & $237(11.2,9.8-12.5)$ \\
\hline Seasonal influenza serotype & & & & \\
H1N1(pdm09) & $94(13.4,10.9-16.0)$ & $85(16.8,13.5-20.1)$ & $90(18.7,15.2-22.2)$ & $79(18.1,14.5-21.7)$ & $348(16.4,14.8-18.0)$ \\
H3N2 & $237(33.9,30.4-37.4)$ & $165(32.6,28.5-36.7)$ & $199(41.4,37.0-45.8)$ & $171(39.1,34.6-43.7)$ & $772(36.3,34.3-38.4)$ \\
\hline
\end{tabular}




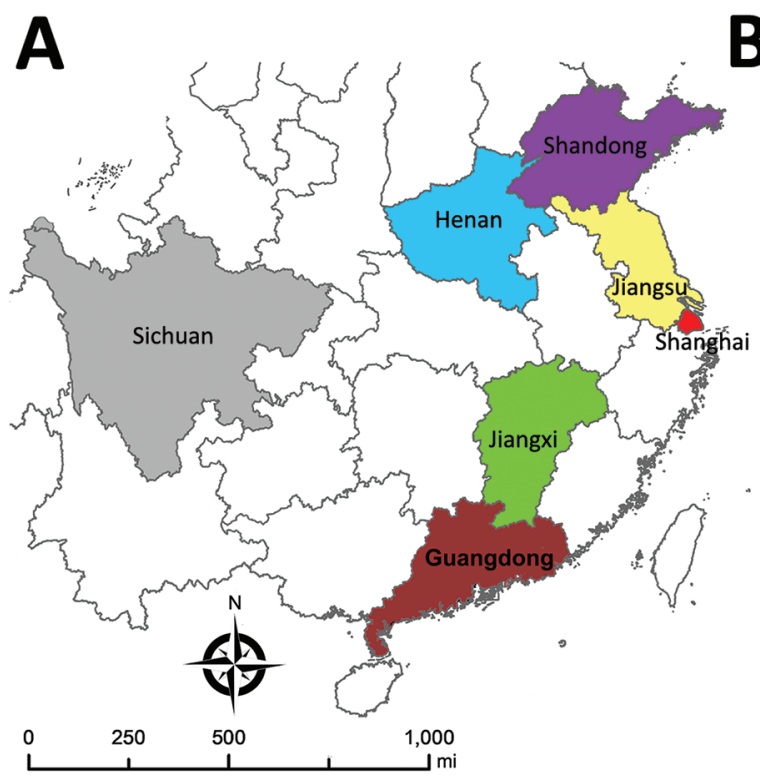

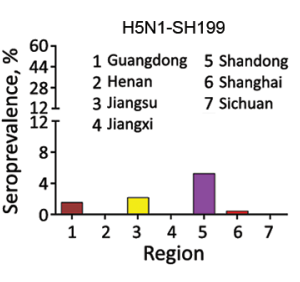
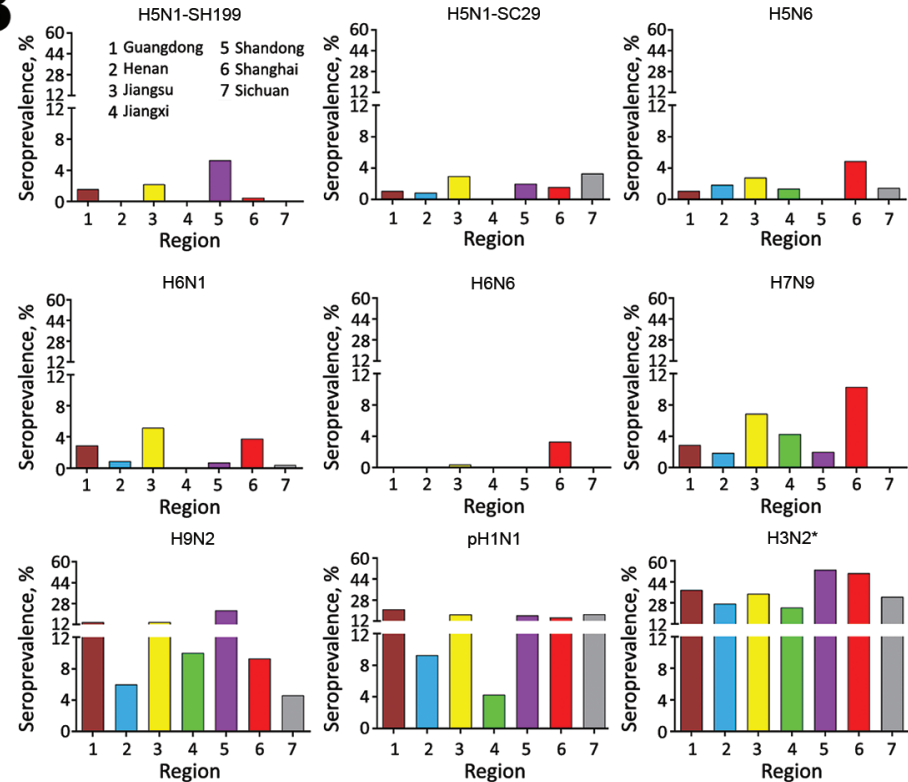

Figure 3. Avian influenza virus seroprevalence in the studied regions of China during December 2014-April 2016. A) Geographic areas included for serosurveillance: 1 municipality, Shanghai, and 6 provinces, Guangdong, Henan, Jiangsu, Jiangxi, Shandong, and Sichuan. B) Seroprevalence against avian influenza A virus subtypes in 4 cross-sectional surveys. Colors on map correspond to colors in bar graphs. *Seasonal influenza virus subtype.

saw no seroconversion for the subtype (Table 4; Figure 4, panel A).

Some participants showed consistently seropositive results, 15 for H7N9 subtype and 41 for H9N2 subtype and a few each for H5N1, H5N6, and H6N1 subtypes (Figure 4, panel B). One participant (no. 14.12GD72) showed HI titers at 1:20 and MN titers at 1:160 to H5N1-SH199 subtype in 4 consecutive surveys (Figure 4, panel C).

\section{Risk Analysis for Asymptomatic AIV Infections}

In the multivariable analysis, we identified demographic and occupational risk factors for poultry workers with asymptomatic infections. For instance, the demographic classification female (adjusted OR [aOR] 2.2, 95\% CI 1.4-3.6), and occupational classification poultry seller (aOR 4.1, 95\% CI 2.2-7.7) appear to be risk factors for H7N9 infection. For H9N2 subtype, female (aOR 1.6, 95\% CI 1.2-2.1) and poultry seller (aOR 1.9, 95\% CI 1.4-2.6) appear to be risk factors for infection. In addition, the number of years working in poultry-related occupations was associated with seroprevalence. In particular, samples from workers reporting $\geq 3$ years of exposure were associated with seroprevalence of H9N2 subtype. Factors associated with increased risk for $\mathrm{H} 5$ infections included being $>55$ years of age, being exposed to ducks, or being exposed to ill or dead poultry (Table 5).

Our study revealed a correlation between the presence of antibodies and seasonal influenza virus infection. We saw an association between the presence of $\mathrm{pH} 1 \mathrm{~N} 1$ virus antibodies and increased seropositivity for H5N1 or H5N6 subtypes, and between occurrence of seasonal $\mathrm{H} 3 \mathrm{~N} 2$ virus antibodies in humans and positive antibody titers for H7N9 virus subtype. We also saw a positive association between elevated H6N1 seropositivity and the presence of antibodies against pH1N1 (aOR 3.0, 95\% CI 1.7-5.4) and H9N2 (aOR 2.6, 95\% CI 1.4-5.0) subtypes (Table 5). Seasonal influenza vaccination history was not a significant risk factor for elevated AIV antibody titers, perhaps because of low vaccination rates.

\section{AIV Circulation in Poultry and Markets}

We collected 6,207 samples from poultry and the environment for AIV screening and detection in this study. In Shanghai, $4.1 \%(20 / 493)$ of samples were positive for H7N9 subtype, as were $8.6 \%$ (41/476) of samples from Jiangsu Province. However, only $0.6 \%(15 / 2,308)$ of samples from Jiangxi Province, $0.6 \%(12 / 2,158)$ of samples from Guangdong Province, and $0.2 \%(1 / 516)$ of samples from Sichuan Province were positive for H7N9 subtype (Appendix Table 10).

For H9N2 subtype, $14.4 \%$ (71/493) of samples from Shanghai, 9.5\% (45/476) from Jiangsu Province, and 8.3\% $(180 / 2,158)$ of samples from Guangdong Province were positive. However, only $4.4 \%(102 / 2,308)$ of samples from Jiangxi Province and 5.5\% (14/256) from Henan Province were positive for H9N2 (Appendix Table 10).

Exploring the correlation between AIV circulation in poultry and seroprevalence in workers in live poultry 

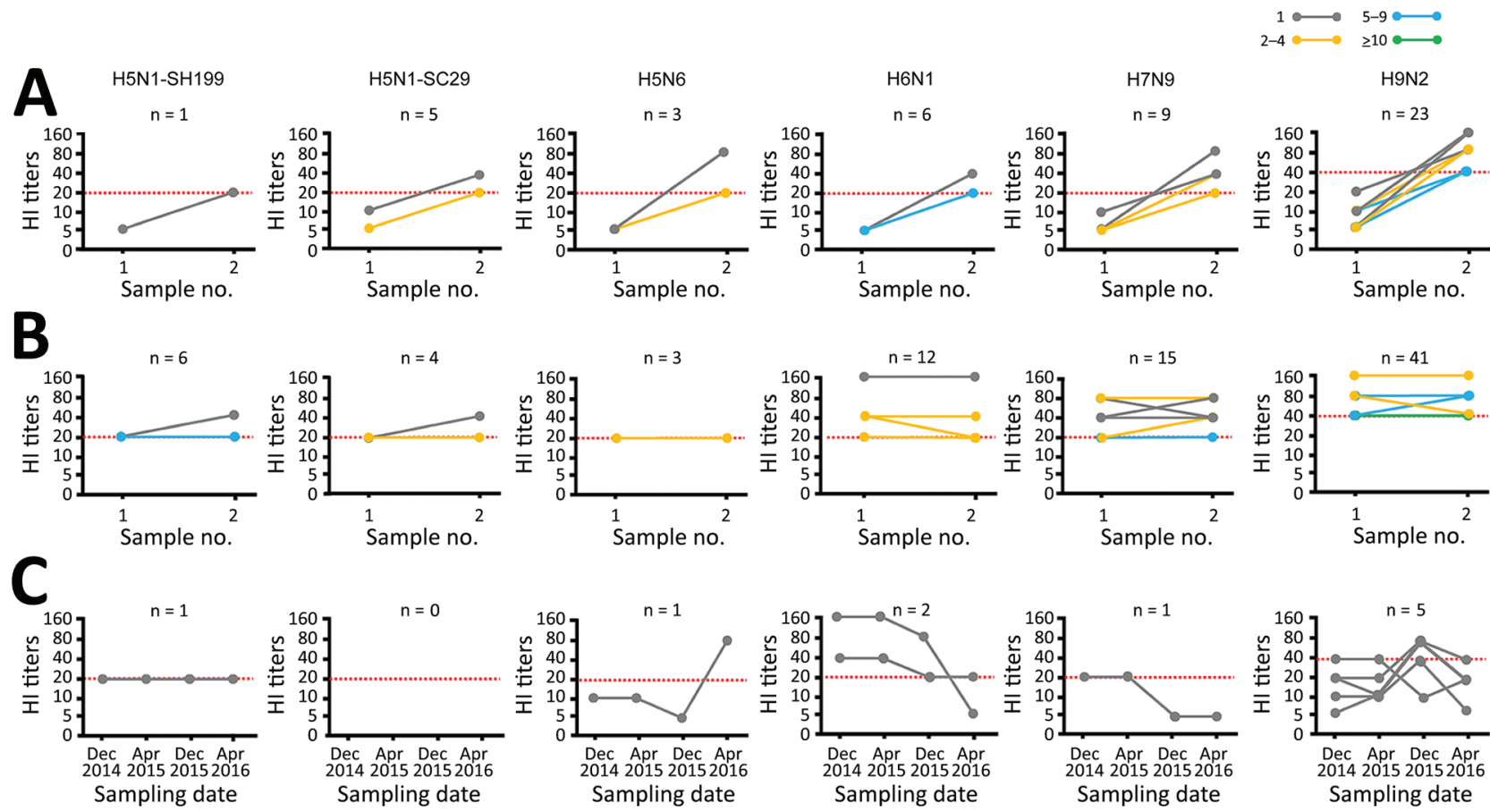

Figure 4. Seroconversion and persistent positivity for avian influenza virus (AIV) A subtypes based on HI titers in a cohort study in China during December 2014-April 2016. Each dot and line connection represents 1 participant. Red dashed lines represent positive cutoff for the HI titers; HI-positive samples were confirmed by a microneutralization assay. A) Comparison of paired samples from participants during 2 surveillance periods showing seroconversion for 6 AIV subtypes. Weighted lines and dots represent participants with seroconversion. B) Number of participants with $>2$ positive sample who were persistently seropositive for 6 AIV subtypes. Weighted lines and dots represent number of participants with seropositivity. C) Antibody titers of representative participants with $>1$ positive sample in the 4 serosurveys. HI, hemagglutinin inhibition.

markets revealed a correlation coefficient of $0.8(\mathrm{p}=0.04)$ for $\mathrm{H} 7 \mathrm{~N} 9$ virus and $0.5(\mathrm{p}=0.28)$ for $\mathrm{H} 9 \mathrm{~N} 2$ virus, indicating that prevalence of local AIVs was statistically correlated with H7N9 subtype seroprevalence. Our results also revealed that AIV prevalence in the different provinces was a key determinant of seroprevalence in the corresponding poultry workers. However, we did not observe a similar trend with other seroepidemic subtypes.

\section{Discussion}

We conducted a longitudinal seroepidemiologic study of occupationally exposed poultry workers in China during December 2014-April 2016. We investigated antibody

\begin{tabular}{|c|c|c|}
\hline \multirow[b]{2}{*}{ Subtype } & \multicolumn{2}{|c|}{ No. $(\%, 95 \% \mathrm{Cl})$ participants } \\
\hline & Seroconversion & Persistently positive \\
\hline H5N1-SH199 & $1(0.2,0-0.9)$ & $6(0.9,0.3-2.0)$ \\
\hline H5N1-SC29 & $5(0.8,0.2-1.8)$ & $4(0.6,0.2-1.6)$ \\
\hline H5N6 & $3(0.5,0.0-1.3)$ & $3(0.5,0.0-1.3)$ \\
\hline H6N1 & $6(0.9,0.3-2.0)$ & $12(1.8,0.8-2.9)$ \\
\hline H6N6 & $4(0.6,0.2-1.7)$ & $0(0.0,0.0-0.6)$ \\
\hline H7N9 & $9(1.4,0.5-2.3)$ & $15(2.3,1.1-3.5)$ \\
\hline H9N2 & $23(3.5,2.1-4.9)$ & $41(6.3,4.4-8.2)$ \\
\hline H10N8 & $0(0-0.6)$ & $0(0-0.6)$ \\
\hline
\end{tabular}

profiles of 7 AIV subtypes that have crossed the species barrier to infect humans, H5N1, H5N6, H6N1, H7N9, H9N2 and H10N8 subtypes, and H6N6 subtype, which is a potential risk to humans. We assessed seroconversion by analyzing paired serum samples from poultry workers and detecting AIV in poultry and the environment in live poultry markets.

H9N2 virus, which plays a role at the animal-human interface, serves as gene donor for H7N9 and H10N8 viruses that infect humans (27). We used a Y280/G9 lineage antigen isolated in samples from Guangdong Province in 2015 as a reference, and its seroprevalence was higher than all other AIV subtypes in our study (Appendix Figure 4). Previous serologic studies also have reported that this strain's seroprevalence consistently is higher than other AIV subtypes in most provinces surveyed in China, reflecting the association between prevalent asymptomatic infections and frequent poultry exposure $(12,16,28)$.

Overall, seroprevalence of antibodies against H9N2 subtype in this study was higher than reported in previous serologic studies in China and the seroprevalence was highest in Shandong Province compared with other provinces. $\mathrm{Li}$ et al. reported a 3.04\% seroprevalence between 2009 and 2011 in occupationally exposed populations (29), and $\mathrm{Yu}$ 
Table 5. Risk analysis for seropositive participants in surveys for avian influenza subtypes among poultry workers, China, 2014-2016* \begin{tabular}{llllll}
\hline Subtypes and variables & Seropositive, no. (\%) & Seronegative, no. (\%) & p value† & OR (95\% Cl) & Adjusted OR (95\% Cl)
\end{tabular} H5Nx

$$
\begin{array}{r}
\text { Age, y } \\
<35
\end{array}
$$$$
35-55
$$$$
>55
$$

Exposed to ducks

Yes $34(45.3)$

No $\quad 41(54.7)$

$8(10.8)$

$40(54.1)$

$26(35.1)$

Exposed to ill or dead poultry

Yes $15(20.0)$

No $60(80.0)$

\begin{tabular}{|c|c|c|c|c|c|}
\hline $\begin{array}{l}\text { Positive } \\
\text { Negative }\end{array}$ & $\begin{array}{l}24(32.0) \\
51(68.0)\end{array}$ & $\begin{array}{c}316(16.4) \\
1,733(84.6) \\
\end{array}$ & $<0.001$ & $\begin{array}{c}2.6(1.6-4.3) \\
\text { Referent }\end{array}$ & $\begin{array}{c}3.1(1.8-4.5) \\
\text { Referent }\end{array}$ \\
\hline \multicolumn{6}{|l|}{ H7N9 } \\
\hline \multicolumn{6}{|l|}{ Sex } \\
\hline $\mathrm{F}$ & $53(64.6)$ & $924(45.2)$ & \multirow{2}{*}{$<0.001$} & $2.2(1.4-3.5)$ & $2.2(1.4-3.6)$ \\
\hline M & $29(35.4)$ & $1,118(54.8)$ & & Referent & Referent \\
\hline \multicolumn{6}{|c|}{ Poultry seller§ } \\
\hline Yes & $70(85.4)$ & $1,173(57.5)$ & \multirow{2}{*}{$<0.001$} & $4.3(2.3-8.0)$ & $4.1(2.2-7.7)$ \\
\hline No & $12(14.6)$ & $867(42.5)$ & & Referent & Referent \\
\hline \multicolumn{6}{|c|}{ No. years of work at live poultry market } \\
\hline$<3$ & $11(13.4)$ & $561(27.5)$ & \multirow[t]{3}{*}{0.017} & Referent & Referent \\
\hline $3-10$ & $46(56.1)$ & $924(45.3)$ & & $2.0(1.1-3.5)$ & $1.8(1.0-3.2)$ \\
\hline$>10$ & $25(30.5)$ & $557(27.3)$ & & $1.7(0.9-3.2)$ & $1.3(0.7-2.5)$ \\
\hline \multicolumn{6}{|c|}{ Seropositivity for seasonal H3N2 virus } \\
\hline Positive & $44(53.7)$ & $743(36.4)$ & \multirow{2}{*}{0.002} & $2.0(1.3-3.2)$ & $1.9(1.2-2.9)$ \\
\hline Negative & $38(46.4)$ & $1,299(63.6)$ & & Referent & Referent \\
\hline \multicolumn{6}{|l|}{ H9N2 } \\
\hline \multicolumn{6}{|l|}{ Age, y§ } \\
\hline$<35$ & $56(23.6)$ & $394(21.0)$ & \multirow[t]{3}{*}{0.004} & $2.1(1.3-3.4)$ & $1.9(1.1-3.3)$ \\
\hline $35-55$ & $156(65.8)$ & $1,115(59.4)$ & & $2.1(1.3-3.2)$ & $1.6(1.0-2.5)$ \\
\hline$>55$ & $25(10.6)$ & 367 (19.6) & & Referent & Referent \\
\hline \multicolumn{6}{|l|}{ Sex } \\
\hline $\mathrm{F}$ & $134(56.5)$ & $843(44.7)$ & \multirow[t]{2}{*}{$<0.001$} & $1.6(1.2-2.1)$ & $1.6(1.2-2.1)$ \\
\hline$M$ & $103(43.5)$ & $1,044(55.3)$ & & Referent & Referent \\
\hline \multicolumn{6}{|c|}{ Poultry seller§ } \\
\hline Yes & $175(73.8)$ & $1,068(56.7)$ & \multirow{2}{*}{$<0.001$} & $2.2(1.6-2.9)$ & $1.9(1.4-2.6)$ \\
\hline No & $62(26.2)$ & $817(43.3)$ & & Referent & Referent \\
\hline \multicolumn{6}{|c|}{ Poultry processor§ } \\
\hline Yes & $67(28.3)$ & 407 (21.6) & \multirow[t]{2}{*}{0.02} & $1.4(1.1-1.9)$ & $1.3(1.0-1.7)$ \\
\hline No & $170(71.7)$ & $1,478(78.4)$ & & Referent & Referent \\
\hline \multicolumn{6}{|c|}{ No. years of work at live poultry market } \\
\hline$<3$ & $37(15.6)$ & $535(28.4)$ & \multirow[t]{3}{*}{$<0.001$} & Referent & Referent \\
\hline $3-10$ & $126(53.2)$ & $844(44.7)$ & & $2.6(1.8-3.7)$ & $2.4(1.6-3.5)$ \\
\hline$>10$ & $74(31.2)$ & $508(26.9)$ & & $2.2(1.5-3.2)$ & $3.0(1.3-3.1)$ \\
\hline \multicolumn{6}{|l|}{ H6N1 } \\
\hline \multicolumn{6}{|c|}{ Seropositivity for $\mathrm{H} 1 \mathrm{~N} 1(\mathrm{pdm} 09)$ virus } \\
\hline Positive & $19(35.9)$ & $321(15.5)$ & \multirow[t]{2}{*}{$<0.001$} & $3.0(1.7-5.4)$ & $3.0(1.7-5.4)$ \\
\hline Negative & $34(64.1)$ & $1,750(84.5)$ & & Referent & Referent \\
\hline \multicolumn{6}{|c|}{ Seropositivity for H9N2 virus } \\
\hline Positive & $13(24.5)$ & $224(10.8)$ & \multirow[t]{2}{*}{0.002} & $2.7(1.4-5.1)$ & $2.6(1.4-5.0)$ \\
\hline Negative & $40(75.5)$ & $1,847(89.2)$ & & Referent & Referent \\
\hline
\end{tabular}

Seropositivity for $\mathrm{H} 1 \mathrm{~N} 1(\mathrm{pdm} 09)$ virus

et al. reported $4.6 \%$ of poultry workers in their study had antibodies against H9N2 virus in 2013 (30). Another previous serologic study in Tai'an, Shandong Province, reported the prevalence of antibodies against H9 subtypes among poultry workers was $\leq 8.5 \%$ during January 2011 -December 2013 (31). Because no uniform standard antibody titer cutoff is available for H9N2 seropositivity, we used a stricter cutoff value for $\mathrm{HI}$ titers, $\geq 1: 40$, and for $\mathrm{MN}$ titers, $\geq 1: 80$, for seroprevalence to avoid overestimation and reduce cross-reactivity with seasonal influenza viruses (32).

The higher seroprevalence in Shandong Province could be explained by 2 possibilities. Participants in this province were all poultry sellers in live poultry markets, an occupation that we noted as a statistically high risk factor 
for seroprevalence. Shandong is ranked as the one of the largest egg-producing provinces in China, and it has a high prevalence of H9N2 in local chicken flocks $(33,34)$, which could indicate that more people are exposed to AIV from the poultry industry in general.

Logistic regression analysis of risk factors showed that occupational characteristics might increase risk for infection. Seropositive participant characteristics and related AIV information provided pivotal seroevidence for subclinical AIV infection risk factors. We noted that the participant characteristics female and poultry seller were risk factors for $\mathrm{H} 7 \mathrm{~N} 9$ and $\mathrm{H} 9 \mathrm{~N} 2$ infection, which coincides with results of previous studies $(18,35)$. Further risk factor analysis indicated that seropositivity for $\mathrm{pH} 1 \mathrm{~N} 1$ virus was a risk factor for $\mathrm{H} 5$ infections with $\mathrm{H} 5 \mathrm{~N} 1$ and $\mathrm{H} 5 \mathrm{~N} 6$ subtypes and for H6N1 infection and that seropositivity for H3N2 subtype was a risk factor for H7N9 infection. In addition, seroprevalence for H6N1 infection also was affected by seropositivity for H9N2 subtypes. Our results might be explained partially by cross-reactivity between HA antigen from different AIV subtypes $(36,37)$. We noted that the prevalence of H7N9 and H9N2 viruses in poultry from local markets was associated closely with seroprevalence for these subtypes in poultry workers. We also noted that the low seasonal influenza vaccination rate $(2.8 \%)$ in poultry workers might have a limited effect on potential cross-reactions between $\mathrm{pH} 1 \mathrm{~N} 1$ and $\mathrm{H} 5$ subtypes and between $\mathrm{H} 3 \mathrm{~N} 2$ and H7N9 subtypes.

We observed higher prevalence for certain AIV subtypes and seroprevalence for certain AIV antibodies in live poultry markets, providing further evidence of cross-species transmission from birds to humans. Since the H7N9 outbreaks of 2013, consensus that AIV was transmitted from birds to humans led the government of China to implement epidemic control measures. The measures, such as closing live poultry markets during influenza season, cleaning and disinfecting live poultry markets daily, and vaccinating poultry, have effectively reduced the chances for human exposure to AIV-contaminated environments and ill poultry $(38,39)$. Our results demonstrate that epidemic control measures aimed at live poultry markets, including their closure, can be highly effective in human AIV infection control $(9,38)$.

Many participants with seropositivity were residents of southern and eastern provinces. Several determinants could account for this observation. First, the high density of live poultry markets, high population density, and expansive live poultry transportation network in these regions could favor large-scale and transboundary AIV spread in poultry, thereby increasing the risk for human infection (40). Second, these regions are rich in water resources, including the Yangtze and Pearl Rivers, as well as many lakes, which are natural habitats for waterfowl and wild birds that serve as natural hosts for various AIV subtypes, including $\mathrm{H} 5 \mathrm{Nx}$ and $\mathrm{H} 9 \mathrm{~N} 2$ viruses, and that continually generate biological threats to public health $(41,42)$. Studies suggest that migratory birds play a role in the evolution and spread of various zoonotic agents, and southeast China is located along the East Asian-Australian flyway, a migratory route for many bird species $(43,44)$.

Our study had several limitations. Despite serious efforts to collect samples from the same participants during follow-up sampling, movement of vendors and poultry workers from target poultry markets reduced the possibility of obtaining paired samples. In addition, the relatively small sample size and use of only 1 location for the control group, Beijing in 2015, could be potential sources of bias.

In conclusion, our study provides serologic evidence of subclinical human AIV infection in an occupationally exposed population of poultry workers and corresponding AIV infection risk factors. Because novel influenza viruses continue to emerge, our results show the need for enhanced etiologic surveillance of AIVs in live poultry markets and humans. Implementing poultry vaccination would also reduce human infection risk. Finally, our results demonstrate the need for active surveillance to foresee dynamic AIV epidemics and inform influenza vaccine development.

\section{Acknowledgments}

We thank the participant poultry workers and staff of the Chinese Center for Disease Control and Prevention at country, prefecture, and provincial levels for making this study possible.

This study was funded by grants from the National Natural Science Foundation of China (NSFC; no. 81502857), the National Grand Project on Prevention and Control of Major Infectious Diseases (no. 2016ZX10004222-003), and the intramural special grant for influenza virus research from the Chinese Academy of Sciences (no. KJZD-EW-L15). W.J.L. is supported by the Excellent Young Scientist Program of the NSFC (grant no. 81822040). G.F.G. is a leading principal investigator of the NSFC Innovative Research Group (grant no. 81621091). The funding bodies played no role in the study design, data collection and analysis, manuscript preparation, or in the decision to publish. The findings and conclusions in this article are those of the authors and do not necessarily represent the official position of the funding agencies.

\section{About the Author}

Dr. Quan was a medical student at the National Institute for Viral Disease Control and Prevention, Chinese Center for Disease Control and Prevention, Beijing, China, during the study. His primary research interests include etiology and serology of influenza viruses and other emerging and reemerging viruses. 


\section{References}

1. Su S, Bi Y, Wong G, Gray GC, Gao GF, Li S. Epidemiology, evolution, and recent outbreaks of avian influenza virus in China. J Virol. 2015;89:8671-6. https://doi.org/10.1128/JVI.01034-15

2. Gao GF. From "A"IV to "Z"IKV: Attacks from emerging and re-emerging pathogens. Cell. 2018;172:1157-9. https://doi.org/ 10.1016/j.cell.2018.02.025

3. Huo X, Cui L, Chen C, Wang D, Qi X, Zhou M, et al. Severe human infection with a novel avian-origin influenza $\mathrm{A}(\mathrm{H} 7 \mathrm{~N} 4)$ virus. Sci Bull. 2018;63:1043-50. https://doi.org/10.1016/ j.scib.2018.07.003

4. Wei SH, Yang JR, Wu HS, Chang MC, Lin JS, Lin CY, et al. Human infection with avian influenza A H6N1 virus: an epidemiological analysis. Lancet Respir Med. 2013;1:771-8. https://doi.org/10.1016/S2213-2600(13)70221-2

5. Han M, Gu J, Gao GF, Liu WJ. China in action: national strategies to combat against emerging infectious diseases. Sci China Life Sci. 2017;60:1383-5. https://doi.org/10.1007/s11427-017-9141-3

6. Liu D, Shi W, Shi Y, Wang D, Xiao H, Li W, et al. Origin and diversity of novel avian influenza A H7N9 viruses causing human infection: phylogenetic, structural, and coalescent analyses. Lancet. 2013;381:1926-32. https://doi.org/10.1016/S0140-6736(13)60938-1

7. Liu J, Xiao H, Wu Y, Liu D, Qi X, Shi Y, et al. H7N9: a low pathogenic avian influenza A virus infecting humans. Curr Opin Virol. 2014;5:91-7. https://doi.org/10.1016/j.coviro.2014.03.001

8. Quan C, Huang T, Chen X, Zhang J, Wang Q, Zhang C, et al. Genomic characterizations of $\mathrm{H} 4$ subtype avian influenza viruses from live poultry markets in Sichuan Province of China, 2014 2015. Sci China Life Sci. 2018;61:1123-6. https://doi.org/10.1007/ s11427-018-9327-4

9. Gao GF. Influenza and the live poultry trade. Science. 2014; 344:235. https://doi.org/10.1126/science.1254664

10. Cui B, Liao Q, Lam WWT, Liu ZP, Fielding R. Avian influenza A/ $\mathrm{H} 7 \mathrm{~N} 9$ risk perception, information trust and adoption of protective behaviours among poultry farmers in Jiangsu Province, China. BMC Public Health. 2017;17:463-76. https://doi.org/10.1186/ s12889-017-4364-y

11. Bai T, Zhou J, Shu Y. Serologic study for influenza A (H7N9) among high-risk groups in China. N Engl J Med. 2013;368:233940. https://doi.org/10.1056/NEJMc1305865

12. Wang M, Fu C-X, Zheng B-J. Antibodies against H5 and H9 avian influenza among poultry workers in China. N Engl J Med. 2009;360:2583-4. https://doi.org/10.1056/NEJMc0900358

13. Ma C, Cui S, Sun Y, Zhao J, Zhang D, Zhang L, et al. Avian influenza A (H9N2) virus infections among poultry workers, swine workers, and the general population in Beijing, China, 2013-2016: A serological cohort study. Influenza Other Respir Viruses. 2019;13:415-25. https://doi.org/10.1111/irv.12641

14. Xin L, Bai T, Zhou JF, Chen YK, Li XD, Zhu WF, et al. Seropositivity for avian influenza H6 virus among humans, China. Emerg Infect Dis. 2015;21:1267-9. https://doi.org/10.3201/ eid2107.150135

15. Sikkema RS, Freidl GS, de Bruin E, Koopmans M. Weighing serological evidence of human exposure to animal influenza viruses-a literature review. Euro Surveill. 2016;21:30388. https://doi.org/10.2807/1560-7917.ES.2016.21.44.30388

16. Khan SU, Anderson BD, Heil GL, Liang S, Gray GC. A systematic review and meta-analysis of the seroprevalence of influenza A(H9N2) infection among humans. J Infect Dis. 2015;212:562-9. https://doi.org/10.1093/infdis/jiv109

17. Yang S, Chen Y, Cui D, Yao H, Lou J, Huo Z, et al. Avian-origin influenza $\mathrm{A}(\mathrm{H} 7 \mathrm{~N} 9)$ infection in influenza $\mathrm{A}(\mathrm{H} 7 \mathrm{~N} 9)$-affected areas of China: a serological study. J Infect Dis. 2014;209:265-9. https://doi.org/10.1093/infdis/jit430

18. Wang X, Fang S, Lu X, Xu C, Cowling BJ, Tang X, et al. Seroprevalence to avian influenza $\mathrm{A}(\mathrm{H} 7 \mathrm{~N} 9)$ virus among poultry workers and the general population in southern China: a longitudinal study. Clin Infect Dis. 2014;59:e76-83. https://doi.org/ 10.1093/cid/ciu399

19. Li LH, Yu Z, Chen WS, Liu SL, Lu Y, Zhang YJ, et al. Evidence for $\mathrm{H} 5$ avian influenza infection in Zhejiang province, China, 2010-2012: a cross-sectional study. J Thorac Dis. 2013;5:790-6. https://doi.org/10.3978/j.issn.2072-1439.2013.12.45

20. World Health Organization. Manual for the laboratory diagnosis and virological surveillance of influenza. Geneva: The Organization; 2011 [cited 2019 Feb 10]. https://www.who.int/ influenza/gisrs_laboratory/manual_diagnosis_surveillance_ influenza/en

21. Qi W, Su S, Xiao C, Zhou P, Li H, Ke C, et al. Antibodies against H10N8 avian influenza virus among animal workers in Guangdong Province before November 30, 2013, when the first human H10N8 case was recognized. BMC Med. 2014;12:205. https://doi.org/10.1186/s12916-014-0205-3

22. Gomaa MR, Kayed AS, Elabd MA, Zeid DA, Zaki SA, El Rifay AS, et al. Avian influenza A(H5N1) and A(H9N2) seroprevalence and risk factors for infection among Egyptians: a prospective, controlled seroepidemiological study. J Infect Dis. 2015;211:1399-407. https://doi.org/10.1093/infdis/jiu529

23. Liu WJ, Tan S, Zhao M, Quan C, Bi Y, Wu Y, et al. Cross-immunity against avian influenza $A(H 7 N 9)$ virus in the healthy population is affected by antigenicity-dependent substitutions. J Infect Dis. 2016;214:1937-46. https://doi.org/10.1093/infdis/jiw471

24. Pawar SD, Tandale BV, Raut CG, Parkhi SS, Barde TD, Gurav YK, et al. Avian influenza H9N2 seroprevalence among poultry workers in Pune, India, 2010. PLoS One. 2012;7:e36374. https://doi.org/10.1371/journal.pone.0036374

25. Bi Y, Chen Q, Wang Q, Chen J, Jin T, Wong G, et al. Genesis, evolution and prevalence of H5N6 avian influenza viruses in China. Cell Host Microbe. 2016;20:810-21. https://doi.org/10.1016/ j.chom.2016.10.022

26. Horby PW, Laurie KL, Cowling BJ, Engelhardt OG, Sturm-Ramirez K, Sanchez JL, et al.; CONSISE Steering Committee. CONSISE statement on the reporting of seroepidemiologic studies for influenza (ROSES-I statement): an extension of the STROBE statement. Influenza Other Respir Viruses. 2017;11:2-14. https://doi.org/10.1111/irv.12411

27. Sun Y, Liu J. H9N2 influenza virus in China: a cause of concern. Protein Cell. 2015;6:18-25. https://doi.org/10.1007/ s13238-014-0111-7

28. Wang Q, Ju L, Liu P, Zhou J, Lv X, Li L, et al. Serological and virological surveillance of avian influenza A virus H9N2 subtype in humans and poultry in Shanghai, China, between 2008 and 2010. Zoonoses Public Health. 2015;62:131-40. https://doi.org/10.1111/ zph. 12133

29. Li X, Tian B, Jianfang Z, Yongkun C, Xiaodan L, Wenfei Z, et al. A comprehensive retrospective study of the seroprevalence of H9N2 avian influenza viruses in occupationally exposed populations in China. PLoS One. 2017;12:e178328. https://doi.org/10.1371/journal.pone.0178328

30. Yu Q, Liu L, Pu J, Zhao J, Sun Y, Shen G, et al. Risk perceptions for avian influenza virus infection among poultry workers, China. Emerg Infect Dis. 2013;19:313-6. https://oi.org/ 10.3201/eid1901.120251

31. Li S, Zhou Y, Song W, Pang Q, Miao Z. Avian influenza virus H9N2 seroprevalence and risk factors for infection in occupational poultry-exposed workers in Tai'an of China. J Med Virol. 2016;88:1453-6. https://doi.org/10.1002/jmv.24483

32. World Health Organization. Recommendations and laboratory procedures for detection of avian influenza $\mathrm{A}(\mathrm{H} 5 \mathrm{~N} 1)$ virus in specimens from suspected human cases. Geneva: The Organization; 2007. [cited 2019 Aug 12 ]. https://www.who.int/ influenza/resources/documents/h5n1_laboratory_procedures 
33. National Bureau of Statistics of China. Statistical Yearbook of China [in Chinese]. Beijing: The Bureau; 2014. [cited 2019 Aug 12]. http://www.stats.gov.cn/tjsj/ndsj/2014/indexch.htm

34. Li Y, Liu M, Sun Q, Zhang H, Zhang H, Jiang S, et al. Genotypic evolution and epidemiological characteristics of H9N2 influenza virus in Shandong Province, China. Poult Sci. 2019;98(9):3488-95. PubMed https://doi.org/10.3382/ps/pez151

35. Ma MJ, Zhao T, Chen SH, Xia X, Yang XX, Wang GL, et al. Avian influenza A virus infection among workers at live poultry markets, China, 2013-2016. Emerg Infect Dis. 2018;24:1246-56. https://doi.org/10.3201/eid2407.172059

36. Khuntirat BP, Yoon IK, Blair PJ, Krueger WS, Chittaganpitch M, Putnam SD, et al. Evidence for subclinical avian influenza virus infections among rural Thai villagers. Clin Infect Dis. 2011; 53:e107-16. https://doi.org/10.1093/cid/cir525

37. Kallewaard NL, Corti D, Collins PJ, Neu U, McAuliffe JM, Benjamin E, et al. Structure and function analysis of an antibody recognizing all influenza A subtypes. Cell. 2016;166:596-608. https://doi.org/10.1016/j.cell.2016.05.073

38. Yuan J, Lau EH, Li K, Leung YH, Yang Z, Xie C, et al. Effect of live poultry market closure on avian influenza A(H7N9) virus activity in Guangzhou, China, 2014. Emerg Infect Dis. 2015;21:1784-93. https://doi.org/10.3201/eid2110.150623

39. Peiris JSM, Cowling BJ, Wu JT, Feng L, Guan Y, Yu H, et al. Interventions to reduce zoonotic and pandemic risks from avian influenza in Asia. Lancet Infect Dis. 2016;16:252-8. https://doi.org/10.1016/S1473-3099(15)00502-2
40. Fournié G, Guitian J, Desvaux S, Cuong VC, Dung H, Pfeiffer DU, et al. Interventions for avian influenza A (H5N1) risk management in live bird market networks. Proc Natl Acad Sci U S A. 2013;110:9177-82. https://doi.org/10.1073/pnas.1220815110

41. Wang D, Yang L, Zhu W, Zhang Y, Zou S, Bo H, et al. Two outbreak sources of influenza A (H7N9) viruses have been established in China. J Virol. 2016;90:5561-73. https://doi.org/ 10.1128/JVI.03173-15

42. Gao GF. For a better world: Biosafety strategies to protect global health. Biosaf Health. 2019;1(1):1-3. https://doi.org/10.1016/ j.bsheal.2019.03.001

43. Tian H, Zhou S, Dong L, Van Boeckel TP, Cui Y, Newman SH, et al. Avian influenza H5N1 viral and bird migration networks in Asia. Proc Natl Acad Sci U S A. 2015;112:172-7. https://doi.org/10.1073/pnas.1405216112

44. Bi Y, Shi W, Chen J, Chen Q, Ma Z, Wong G, et al. CASCIRE surveillance network and work on avian influenza viruses. Sci China Life Sci. 2017;60:1386-91. https://doi.org/10.1007/s11427017-9251-2

Address for correspondence: George F. Gao or William J. Liu, Chinese Center for Disease Control and Prevention, 155 Changbai Rd, Changping District, Beijing 102206, China; email: gaofu@chinacdc.cn or liujun@ivdc.chinacdc.cn; Hongjie Yu, Fudan University School of Public Health, No. 138 Yixueyuan Rd, Xuhui District, Shanghai, 200032, China; email: yhj@fudan.edu.cn

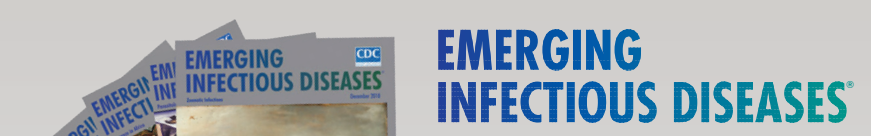 \\ December 2018 Zoonotic Infections \\ - Outbreak of HIV Infection Linked to Nosocomial Transmission, China, 2016-2017 \\ - Autochthonous Human Case of Seoul Virus Infection, the Netherlands. \\ - Reemergence of St. Louis Encephalitis Virus in the Americas \\ - Spatial Analysis of Wildlife Tuberculosis Based on a Serologic Survey Using Dried Blood Spots, Portugal \\ - Comparison of Highly Pathogenic Avian Influenza H5 Guangdong Lineage Epizootic in Europe (2016-17) with Previous HPAI H5 Epizootics \\ - Capnocytophaga canimorsus Capsular Serovar and Disease Severity, Helsinki, Finland, 2000-2017 \\ - Rat Lungworm Infection in Rodents Across Post-Katrina New Orleans, Louisiana \\ - Crimean-Congo Hemorrhagic Fever Virus, Mongolia, 2013-2014 \\ - Emerging Multidrug-Resistant Hybrid Pathotype Shiga toxin- producing Escherichia coli $\mathrm{O} 80$ and Related Strains of Clonal Complex 165, Europe. \\ - Terrestrial Bird Migration and West Nile Virus Circulation, United States \\ - Substance Use and Adherence to HIV Preexposure Prophylaxis for Men Who Have Sex with Men \\ - Genomic Characterization of $\beta$-Glucuronidase-Positive Escherichia coli 0157:H7 Producing Stx2a \\ - Highly Pathogenic Clone of Shiga Toxin-Producing Escherichia coli O157:H7, England and Wales \\ - CTX-M-65 Extended-Spectrum $\beta$-Lactamase-Producing Salmonella enterica Serotype Infantis, United States \\ - Novel Type of Chronic Wasting Disease Detected in Moose (Alces alces), Norway \\ - Survey of Ebola Viruses in Frugivorous and Insectivorous Bats in Guinea, Cameroon, and the Democratic Republic of the Congo, 2015-2017 \\ - Prevalence of Avian Influenza A(H5) and A(H9) Vuses in Live Bird Markets, Bangladesh \\ - Rat Hepatitis E Virus as a Cause of Persistent Hepatitis after Liver Transplant \\ - Influences of Community Interventions on Zika Prevention Behaviors of Pregnant Women, Puerto Rico, July 2016-June 2017 \\ - Emergent Sand Fly-Borne Phleboviruses in the Balkan Region

